\title{
Numerical Evaluation of Settlement of Strip Footing Resting on Cavity and Weak Soil Profile
}

\author{
Mohammed S. Hussain \\ Department of Civil Engineering, College of Engineering, University of Duhok, Duhok, Kurdistan Region, Iraq
}

\author{
${ }^{*}$ Corresponding author: \\ Mohammed S. Hussain, \\ Department of Civil \\ Engineering, College of \\ Engineering, University \\ of Duhok, Duhok, \\ Kurdistan Region, Iraq. \\ E-mail: mohammed@uod.ac
}

Received: 10 February 2021

Accepted: 27 April 2021

Published:30 June 2021

\section{DOI}

10.25156/ptj.v11n1y2021.pp87-97 \begin{abstract}
A B S TR A C T
This study numerically investigates the effects of different subsurface sources of weaknesses within a soil profile on the settlement of a strip footing using the finite element method (FEM). During the first phase of the study, the influences of size, shape, depth, and distance of cavity from the center of the footing are evaluated. It is noted that the settlement of foundation is increased when the cavity is located at smaller depths and closer to its center. It is concluded that there is a critical zone, where the risk level of settlement (especially differential settlement) due to the cavity is high. The depth of this critical zone is found to be $2.5 B$ (where $B$ is the width of the footing) below the simulated loading area. In the second phase of the study, increasing the degree of weakness of a certain low stiffness layer within the soil profile below the loaded area is simulated as another factor that increases the settlement risks. It is shown that the depth of this weak layer highly controls the settlement of footing even if it is situated at depths $>2.5 B$.
\end{abstract}

Keywords: Numerical modeling; Settlement; Weak soils; Cavity; Strip footing

\section{INTRODUCTION}

In geotechnical engineering the term "weak and soft soils" is usually used for foundation materials characterized with high compressibility and low shear strength. Soft clays, organic soils, and poor fills are some examples of these soils. The stability and settlement problems that often result to serve damages to engineering constructions and structures even under small-superimposed loads are the main risk factors of this type of soils. There are other sources of weakness such as subsurface cavities that also reduce the mechanical properties of the foundation materials. According to Wang et al. (2001), subsurface ground cavities could be formed: (i) Naturally in soluble rocks (i.e. salt beds, gypsum, chalk, limestone, and carbonate rocks) and soils containing soluble materials or (ii) artificially due to underground human activities (i.e. services, tunneling, and mining activities).

In general, ground cavities are geologic features resulting from water erosion of soluble rocks. The water erosion process is usually associated with seepage forces as a result of seasonal variation in groundwater flow (Sabouni and Airan, 2018). The percolation of stored rainfall, flood, and other surface water into ground layers can result in creation of "sinkhole" as a more serious type of cavities (Augarde et al., 2003). Some parts of Iraq, especially in the west, northwest and southwest (including some parts of Kurdistan region), are covered with Gypseous soils at shallow depth. The presence of large amounts of gypsum, appearing as large solid masses, increases the risk of creation of large voids in this type of soils, when subjected to changes in water content (Khattab and Khalil, 2009, Schanz and Karim, 2018). These soils are usually stiff when they are dry, but they are highly affected by water interaction. When these soils are soaked and/or leached by water, the gypsum is dissolved, and with time, voids, and cavities are created, which may lead to sudden settlement and collapse (Schanz and Karim, 2018). In addition, these voids generate apertures (passages) in soils that help in water streaming and dissolution of more of the gypsum.

Al-Taie (2004) and Fattah et al. $(2014,2018)$ used a series of laboratory tests to study the behavior of laterally and vertically loaded piles embedded in sandy soils, including the effects of cavities. In their studies, due to the presence of the cavity, the ultimate failure load of the piles was significantly reduced, and their settlement was increased. Khattab and Khalil (2009) investigated the effects of a single cavity on settlement and stress distribution of the isolated and strip footings using Plaxis 2D finite element software. For all the tested cases, a depth ranging between 1.5 and $2 B$ below the footing base was defined ( $B$ is the width of footing), where the effect of settlement due to cavity is large. In the parametric study conducted by Tahmasebipoor et al. (2012), the stability of a geotextile-reinforced soil above an underground 
cavity was numerically evaluated by Plaxis $2 \mathrm{D}$. The results showed that by increasing the stiffness, the number and length of reinforcement layers, the vertical stresses and the resulting maximum settlement were decreased. Farid (2015) utilized the FEM to simulate the settlement of shallow foundations resting on limestone containing cavities. The simulation was based on the soil properties of the Riyadh region, Saudi Arabia. In this region, the majority of the buildings are designed on limestone, which is the main local rock formation of the area that contains cavities. It was concluded that due to grouting of the cavities, the settlement reduced by 3-10 times for isolated footing and by $1.5-3$ times for mat foundations. Recently, Plaxis 3D Foundation software has been used by Sabouni and Airan (2018) to numerically analyze the settlement of different footing scenarios in a real case study in Abu Dhabi, UAE. The considered case study was a sports hall resting on a soil profile containing relatively shallow cavities. They recommended the combination of pile foundation and grouting of the available cavities as an effective foundation option for the studied structure.

Al-Jazaairry and Sabbagh (2017) used Plaxis software to study the effects of cavities on the load carrying capacity of strip footings subjected to inclined load. In their parametric study, changes in the angle of inclination of load, depth $(Z / B)$, and distance $(X / B)$ of circular cavity from the center of footing and size of cavity $(D / B)$ were considered. It was suggested that by increasing the cavity size (diameter), the load carrying capacity of the footing is decreased. Furthermore, when the cavity was deeper than $(Z=5 B)$ its impact on the calculations could be negligible. This was also the case when the position of the cavity in the horizontal distance $X / B$ was $>2.4-3$; and when the load inclination angle increased to $30^{\circ}$ or more measured from vertical axis. Similarly, many of the previous studies available in the literature such as Hossain et al. (2006), Ghazavi and Soltanpour (2008), Peng et al. (2006), Lavasan et al. (2016), Kapoor et al. (2019), Luo et al. (2019), and Zhao et al. (2021) have focused on the effects of underground cavities on the bearing capacity of the foundation rather than settlement.

In this study, the effects of presence of both the ground cavity and the weak soil layer on the vertical settlement of a hypothetical case study of strip footing are simulated using the finite-element method. Plaxis v.8.2 is used to simulate this geotechnical soil-foundation system in $2 \mathrm{D}$. A parametric study is carried out. During the first phase of the study, the effects of shape, size, depth, and horizontal distance of the cavity from the center of the foundation are investigated. For the second phase, the effects of stiffness and depth of a single weak soil layer on the settlement of the same footing are simulated.

\section{DETAILS OF THE HYPOTHETICAL CASE STUDY}

The studied example involves the construction and loading of a $2 \mathrm{~m}$-wide strip footing placed on a clay layer [Figure 1]. The assumed thickness of the strip footing is $0.5 \mathrm{~m}$, and the total applied load on the footing including its selfweight is $150 \mathrm{kN} / \mathrm{m}$. The thickness of the clay layer is $10 \mathrm{~m}$, overlying a stiff rock layer. The rock layer is not included in the geometry; instead, an appropriate boundary condition is applied at the bottom of the clay layer. This plain strain model of the soil-foundation system is simulated using Plaxis v.8.2 in 2D. The mesh of the model consists of 1293 elements and 10624 nodes, and it is generated with 15-node element type. The application of the 15-node triangular elements was recommended by the software to increase accuracy. However, its application is more time consuming, because the mesh created by this type of element is actually finer and much more flexible than the mesh composed of 6-node elements. Excavation, installation of footing and loading are the defined construction stages considered in the model. For the settlement analysis, the Mohr-Coulomb model is used to define the type of soil material. The properties of the clay layer and the footing are listed in Table 1.

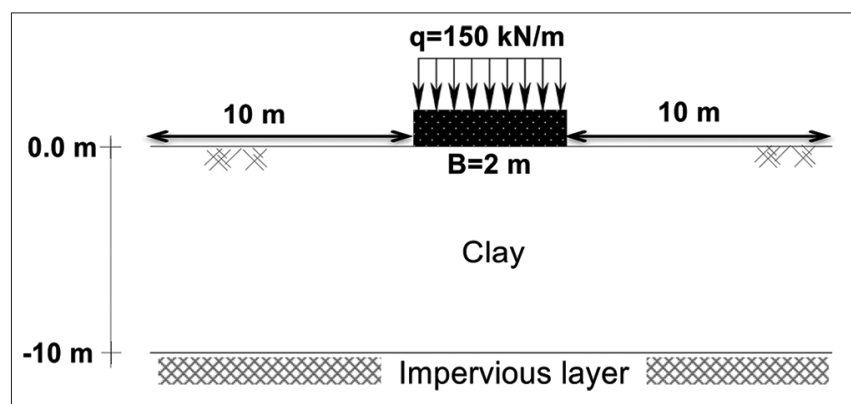

Figure 1: Soil profile and properties of the case study example

Table 1: Material properties of the soil and footing

\begin{tabular}{llcl}
\hline Parameters & Name & Value & Unit \\
\hline Type of material behavior & - & Drained & - \\
Permeability & $k x=k y$ & $8.50 \times 10-5$ & $\mathrm{~m} / \mathrm{d}$ \\
Young's modulus (constant) & Eref & 10000 & $\mathrm{kN} / \mathrm{m}^{2}$ \\
Unit weight above water table & $\gamma$ total & 17 & $\mathrm{kN} / \mathrm{m}^{3}$ \\
Soil & & & \\
$\quad$ Saturated unit weight & $\gamma s a t$ & 20 & $\mathrm{kN} / \mathrm{m}^{3}$ \\
Poisson's ratio & $v$ & 0.3 & - \\
Cohesion (constant) & $C$ & 20 & $\mathrm{kN} / \mathrm{m}^{2}$ \\
Friction angle & $\Phi$ & 30 & \\
Footing & & & \\
$\quad$ Normal stiffness & $E A$ & $1.750 \times 107$ & $\mathrm{kN} / \mathrm{m}$ \\
Flexural rigidity & $E l$ & $3.650 \times 105$ & $\mathrm{kN} / \mathrm{m}^{2} / \mathrm{m}$ \\
Equivalent thickness & $d$ & 0.5 & $\mathrm{~m}$ \\
Weight & $w$ & 12.5 & $\mathrm{kN} / \mathrm{m} / \mathrm{m}$ \\
Poisson's ratio & $v$ & 0.2 & - \\
\hline
\end{tabular}


Figure 2 shows the final deformed mesh and contours of the vertical displacements at the end of the calculation phases. The maximum amount of settlement is $47.6 \mathrm{~mm}$ estimated at the center of the foundation.

The calculated FEM settlement value of the footing center is compared with the theoretical equation (Equation 1) suggested by Poulos and Davis (1974) for strip footing. The equation is for calculation of settlement at the corner of the flexible footing.

$$
\rho=\frac{q_{0} H}{\pi E} m . I
$$

where $\varrho$ is the elastic settlement, $q_{0}$ is the net applied pressure to the foundation; $m$ is number of footing corners contributing to settlement; $H$ is the soil profile depth, and $I$ is the displacement influence factor depends on Poisson's ratio and $B^{\prime} / H$ ratio. To estimate the maximum settlement at the center of footing, the values of $B^{\prime}=B / 2=1.0 \mathrm{~m}$ and $m=2$ are used accordingly. The $I$ value equal to 0.5 is used, which is obtained from the provided chart by (Poulos and Davis, 1974). The calculated maximum settlement value from Equation (1) is $47.7 \mathrm{~mm}$. Therefore, this shows that the numerical result is in a good agreement with the analytical outcome.

\section{PARAMETRIC STUDY}

The effects of ground cavity and also weak layer on the vertical settlement of the studied strip footing are evaluated in this research work. In the first phase of the study, the presence of a single opened area under the footing is used to represent the cavity feature. In the second phase, the weak layer is represented by introducing a layer of soil material with low stiffness (i.e. low value of modulus of

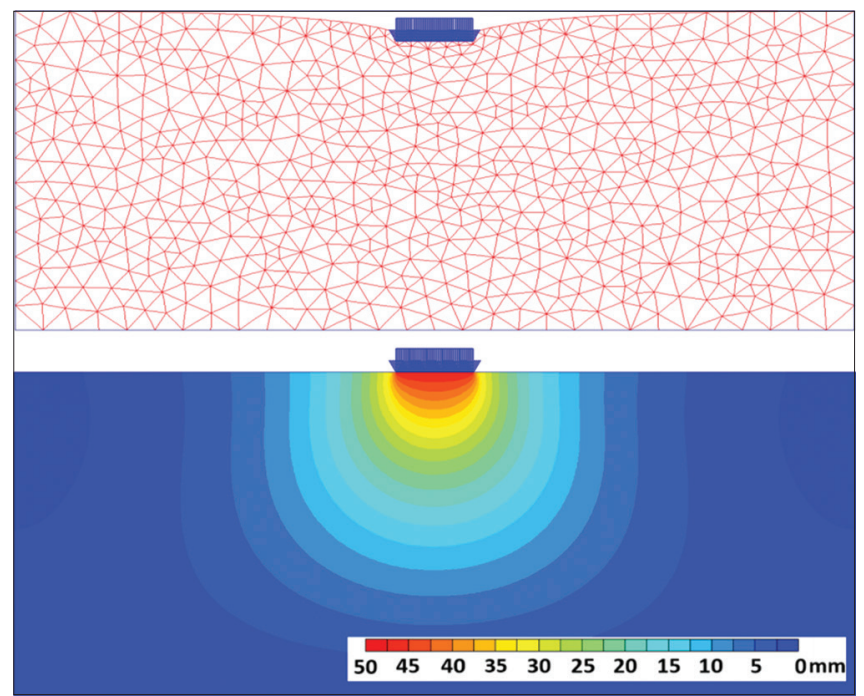

Figure 2: Deformed mesh and vertical displacement contours of the model with no-weaknesses elasticity). In each of these phases, the effects of different parameters on the settlement responses of the loaded area are studied within the concept of the parametric analysis, and the results are compared with the original model with no weakness.

\section{Soil Layer with Cavity}

The purpose of this analysis is to investigate the impact of a single cavity, as a weak zone, within the soil profile on settlement of the footing. The cavity is defined by inserting a closed cluster within the model; and without assigning any soil material to it during all the calculation stages. The influences of three different geometrical shapes of cavity (i.e. circular, rectangular, and square) are evaluated. Table 2 summarizes the seven cases of the defined cavity, which are employed with different sizes and shapes. Within this evaluation, the effects of both depth $(Z c)$ and distance $(X c)$ of the outlined cavity on the results are investigated. $Z c$ is the depth measured below the foundation base to the cavity centerline, and $X_{c}$ is the horizontal distance of the cavity center from the centerline of the footing [Figure 3]. Cases 1,2, and 3 of the cavities are chosen with the same cross-section area to highlight the effects of the cavity shape. Comparison of the results obtained from these three scenarios with other larger shapes in Cases 4-7 will help to identify the general implications of the cavity size.

\section{Effects of depth of cavity on settlement}

In a series of simulation models, the above tabulated cases of cavity are defined in a model at different depths $(Z)$ ranging from 0.5 to $7 \mathrm{~m}$ below the foundation level with 0.5 $\mathrm{m}$-depth intervals. The results show progressive decline in the settlement values by the presence of the cavity at greater depths. For all simulated scenarios of $Z$ introduced within the Case-1 with small circular cavity, the footing is almost in stable condition in terms of differential settlement and this is due to symmetric positioning of the cavity with respect to the axis of surface footing. The maximum value of differential settlement is about $3 \mathrm{~mm}$, which is an insignificant value. Differential settlement is determined as a difference in vertical settlement values between points $A$ and $C$ [Figure 3]. Figure 4 a shows the displacement values

Table 2: Different cases of cavities used in the numerical modelling

\begin{tabular}{llccl}
\hline Cases & Shape & $\begin{array}{c}\text { Dimensions } \\
(\mathbf{c m})\end{array}$ & $\begin{array}{c}\text { Cross- } \\
\text { sectional } \\
\text { area }\left(\mathrm{m}^{2}\right)\end{array}$ & Direction \\
\hline Case-1 & Circular & $\phi=31$ & 0.075 & - \\
Case-2 & Square & $27.4 \times 27.4$ & 0.075 & - \\
Case-3 & Rectangular & $25 \times 30$ & 0.075 & Longitudinal \\
Case-4 & Rectangular & $25 \times 50$ & 0.125 & Longitudinal \\
Case-5 & Rectangular & $25 \times 50$ & 0.125 & Transverse \\
Case-6 & Circular & $\phi=39.8$ & 0.125 & - \\
Case-7 & Circular & $\phi=62$ & 0.3 & - \\
\hline
\end{tabular}


of the top and bottom surfaces of the cavity measured in different cases of $Z_{c}$ of this scenario (Case-1). In general, the top surface of the cavity experiences a larger amount of settlement than the bottom surface at all the studied depths of $Z_{i}$. By subtraction of these two values, the largest amount of vertical deformation of the cavity (about $18.5 \mathrm{~mm}$ ) is measured in the cases with $Z_{c}=2.5 \mathrm{~m}$ manifesting the instability status of the cavity.

A similar settlement modeling process to Case-1 is repeated by fixing the cavity at distance $X_{c}=1 \mathrm{~m}$ away from the footing center, below the right corner point, but at different depths. The variations of displacement with $Z$ for this new scenario at Points A, B, and C [Figure 3] of the footing are illustrated in Figure $4 \mathrm{~b}$ As shown in the figure, the footing is at more critical condition than the aforementioned scenario of the same cavity with $X=0$. The maximum amount of differential settlement $(22.9 \mathrm{~mm})$ is resulted when the cavity is placed at depth $0.5 \mathrm{~m}$ below the base of footing

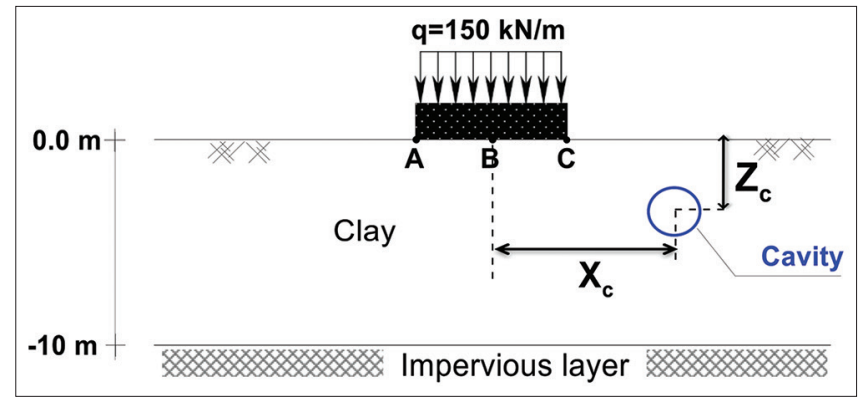

Figure 3: Cavity properties used in the parametric study near to its corner point- $C$, and it steadily approaches to zero at the cavity depth $>3 \mathrm{~m}$. The effects of distance of the cavity from center of footing in this mechanism are discussed in the next section. The patterns of variations of the displacement in both scenarios of this small circular cavity with $X_{c}=0 \mathrm{~m}$ and $X_{c}=1.0 \mathrm{~m}$ are illustrated in Figure 5 .

In an attempt to investigate the validity of the concluding trends of the results with $Z_{c}$ for other geometrical shapes of cavities, a similar modeling is repeated for Cases 2-7 [Table 2]. Figures 6 and 7 present the variations in the displacement values of the footing in all these scenarios with $X=0.0 \mathrm{~m}$ and $X=1.0 \mathrm{~m}$, respectively. In general, for both horizontal positions of $X$, all these cases of the cavity follow a similar trend to Case- 1 . The results of simulation of different shapes of cavities in the first scenario of $X_{c}$ with the cavity located beneath the centerline of the footing [Figure 6], show that the settlements of the footing center (point B) and its corner (point C) increase with $Z$ up to depth of $2.5 \mathrm{~m}$ and then start to decrease and finally become stable at depths $>5 \mathrm{~m}(\approx 2.5 \mathrm{~B})$. In other words, if the cavity is placed at shallower depth than $2.5 \mathrm{~B}$, the settlement is high. Consequently, this territory of the cavity effects within the soil layer can be defined as a critical zone. Figure $6 c$ shows that due to occurrence of the cavity in the depths below the center of footing, the induced risks of differential settlement are low. The average calculated differential settlement for all the seven cases simulated in this scenario is ranged between -2 and $3 \mathrm{~mm}$. The negative sign of these settlement values

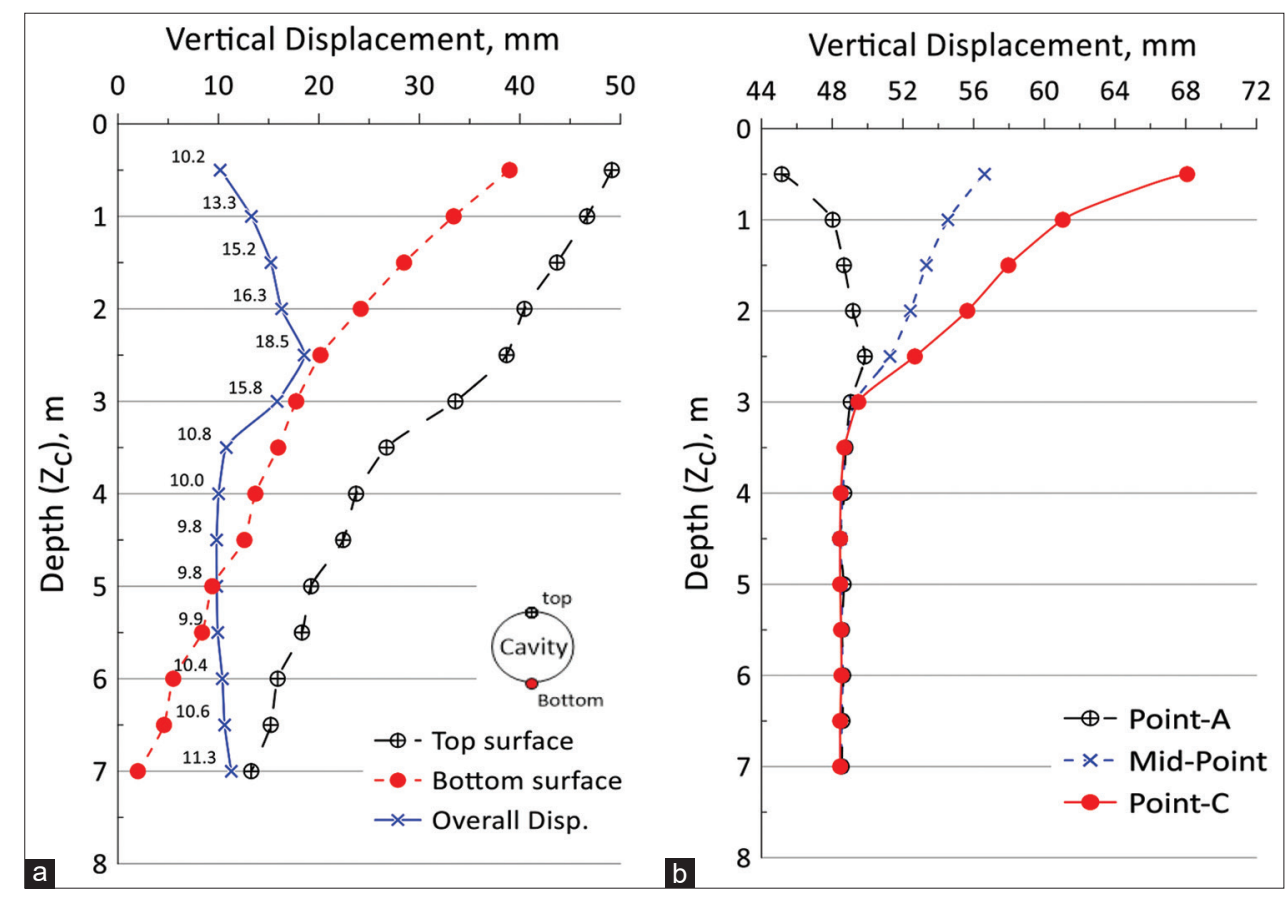

Figure 4: Variation of vertical displacements of both footing and cavity with $Z_{c}$ in Case-1 of a small circular cavity. (a) $X_{c}=0.0 \mathrm{~m}$ (for Cavity) (b) $X_{c}=1.0 \mathrm{~m}$ (for Footing) 

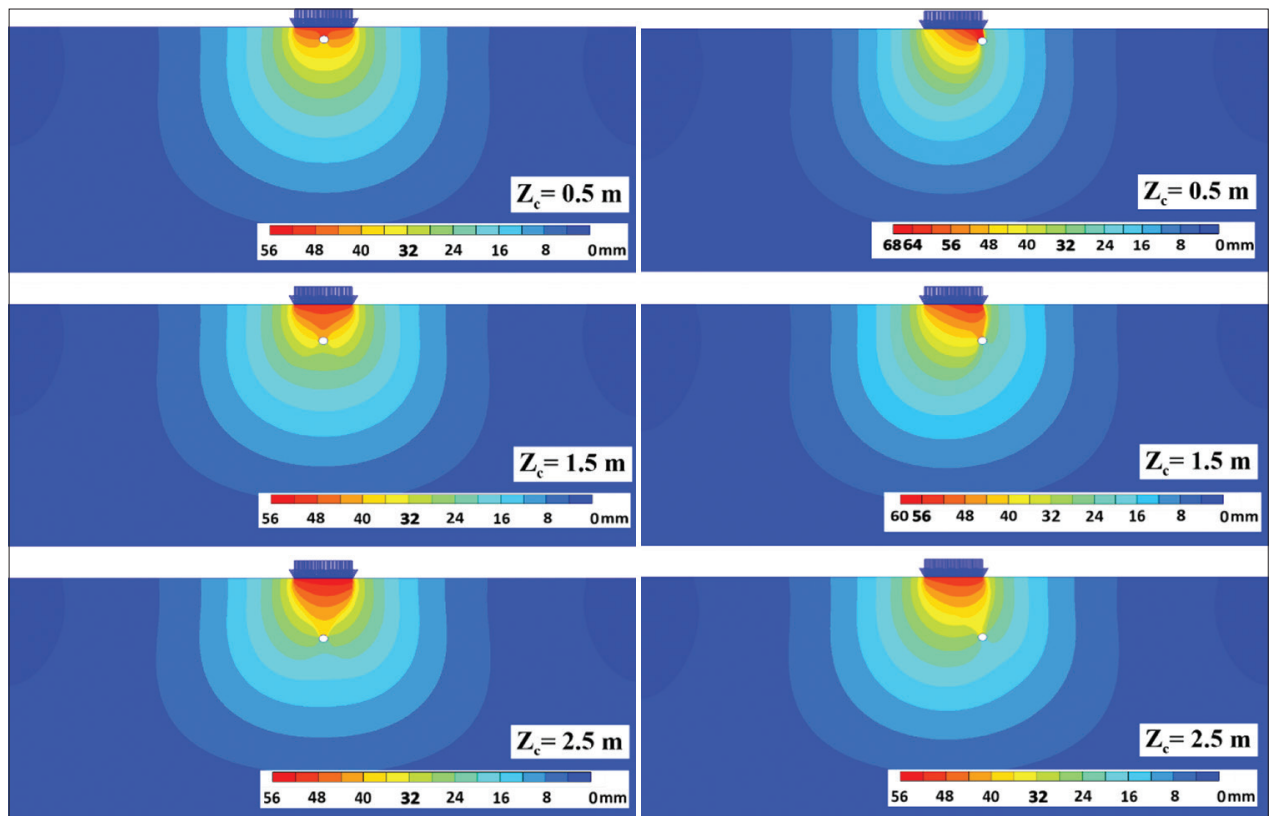

Figure 5: Shadings of the vertical displacement for the Case-1 of a small circular cavity. (a) $X_{c}=0.0 \mathrm{~m}$ (b) $X_{c}=1.0 \mathrm{~m}$

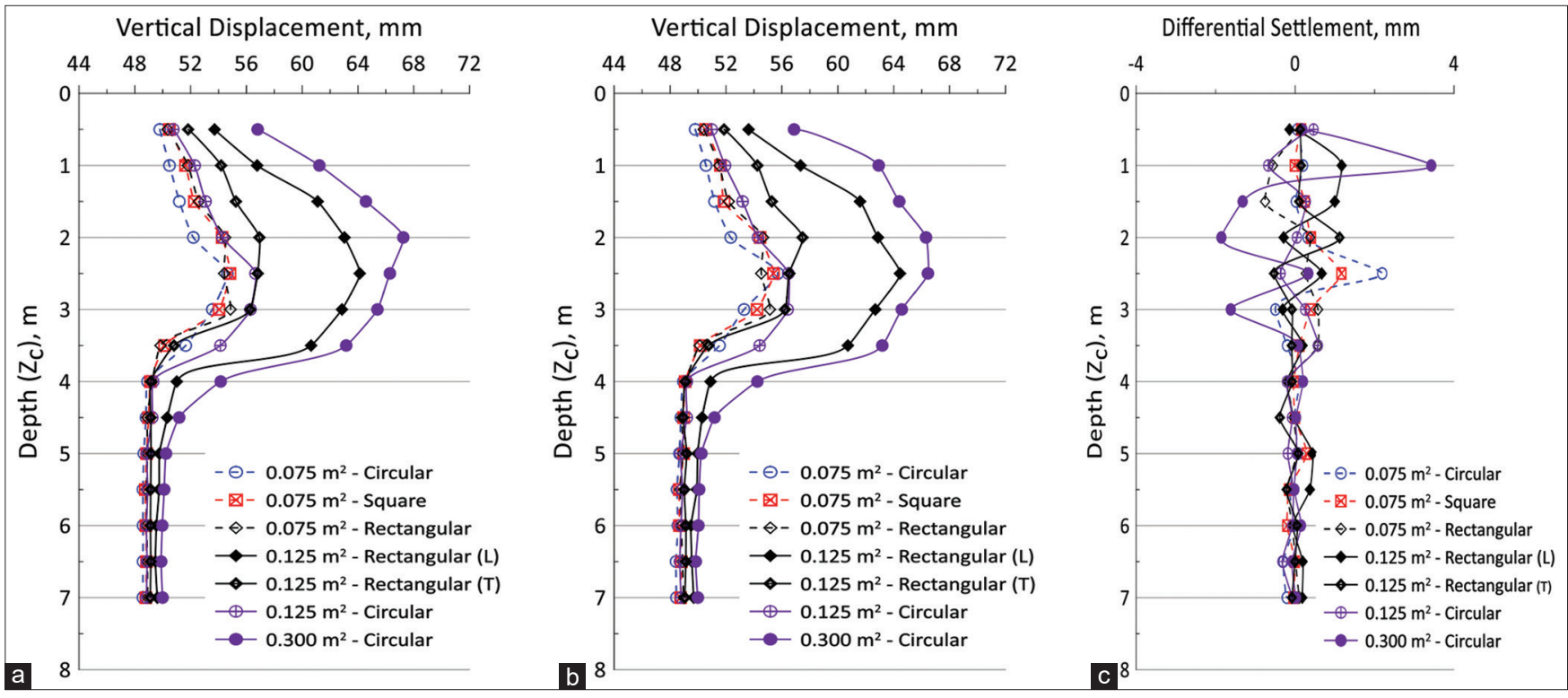

Figure 6: Variation of vertical and differential settlements of the footing with $Z_{c}$ in all seven scenarios of the cavity located at $X_{c}=0.0 \mathrm{~m}$. (a) Point B (Mid-point) (b) Point C (c) Differential settlement

implies that the footing tilted toward the other (opposite) corner (point A).

In this study, the zone with depth $<2 \mathrm{~m}$ is almost equivalent to the area occupied by the soil wedge defined by Terzaghi under the loaded footing. According to Terzaghi's theory, during the loading process this wedge zone of soil with depth equal to $0.5 \tan (45+\varnothing / 2)$ sinks into the ground and relatively remains intact, undeformed and in the elastic state due to the cohesion and adhesion between the base of the footing and the soil (Coduto et al., 2016). In the current scheme of the analysis the void or cavity is positioned symmetrically with respect to the axis of surface strip footing $\left(X_{C}=0\right)$ and thus, with the $\left(Z_{C}=2.5 \mathrm{~m}\right)$ the cavity is nearly situated under the wedge tip. The results of vertical displacement analysis at top and bottom surfaces of the void and also shear strain analysis for all the studied cavity shapes and sizes indicate the largest instability status of the cavity wall at this depth in consequence. For instance, the results of shear strain variations of the small circular cavity (case 1) located at $Z_{C}$ of $0.5 \mathrm{~m}, 2.5 \mathrm{~m}$, and $3.5 \mathrm{~m}$ are presented in Figure 7. It is clear from this figure that due to the missed confinement with the presence of the cavity or the void, the shear strain is generated around the 
void. This instability in the cavity walls increased for the case with $Z_{C}=2.5 \mathrm{~m}$, where the overall pattern of failure is progressed toward the cavity and consequently results in large settlement of the footing. The similar local shear mode of failure has also been reported by Lavasan et al. (2016) and Zhao et al. (2021) that causes an instability in the cavity walls and thus induces a lower bearing capacity. At the greater cover or overburden depth $(>2.5 \mathrm{~m})$, the expansion of induced shear strain is decreased and the cavity no longer has a significant effect on the footing settlement.

As illustrated in Figure 8, the positioning of the cavity at shallow depths and below the sides of footing increases the excessive vertical and differential settlements. Al-Jazaairry and Sabbagh (2017) also confirmed this finding in terms of bearing capacity. They argued that this may also contribute to punching shear failure in cases of cavity being close to the foundation. In the current study, these effects are negligible at the depth of $5 \mathrm{~m}(\approx 2.5 \mathrm{~B})$, which is considered to be the critical depth. In terms of spacing, the assessed horizontal distance of cavity at $X_{C}=1 \mathrm{~m}$ $(\approx 0.5 \mathrm{~B})$ proves to be the most problematic condition for all simulated cases of cavities of different shapes and sizes. The displacement responses of the footing by positioning a small cavity of Case- 1 at different horizontal distances $\left(X_{C}\right)$ from its centerline, with $X_{C}=0,0.5,1,1.5$, and $2 \mathrm{~m}$, are shown in Figure 9 where, both vertical and differential
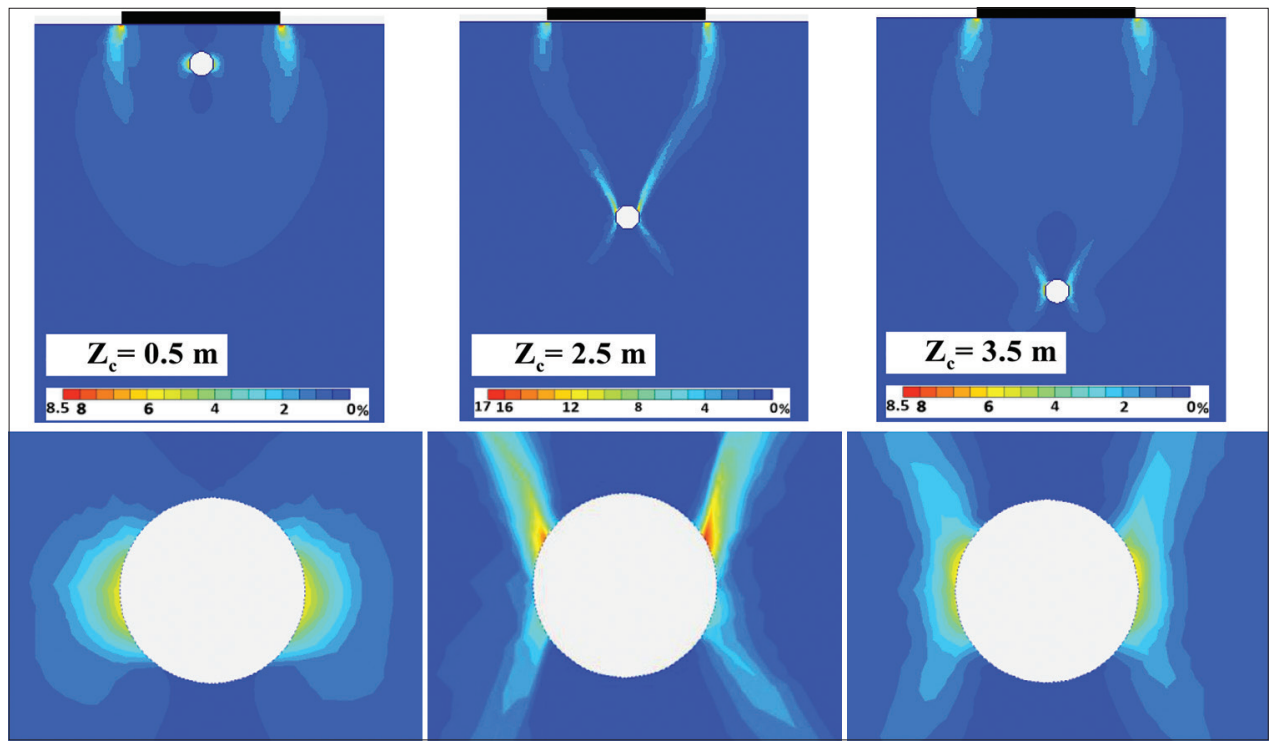

Figure 7: Shear strain distribution under footing for the Case-1 of a small circular cavity located at $X_{c}=0.0 \mathrm{~m}$

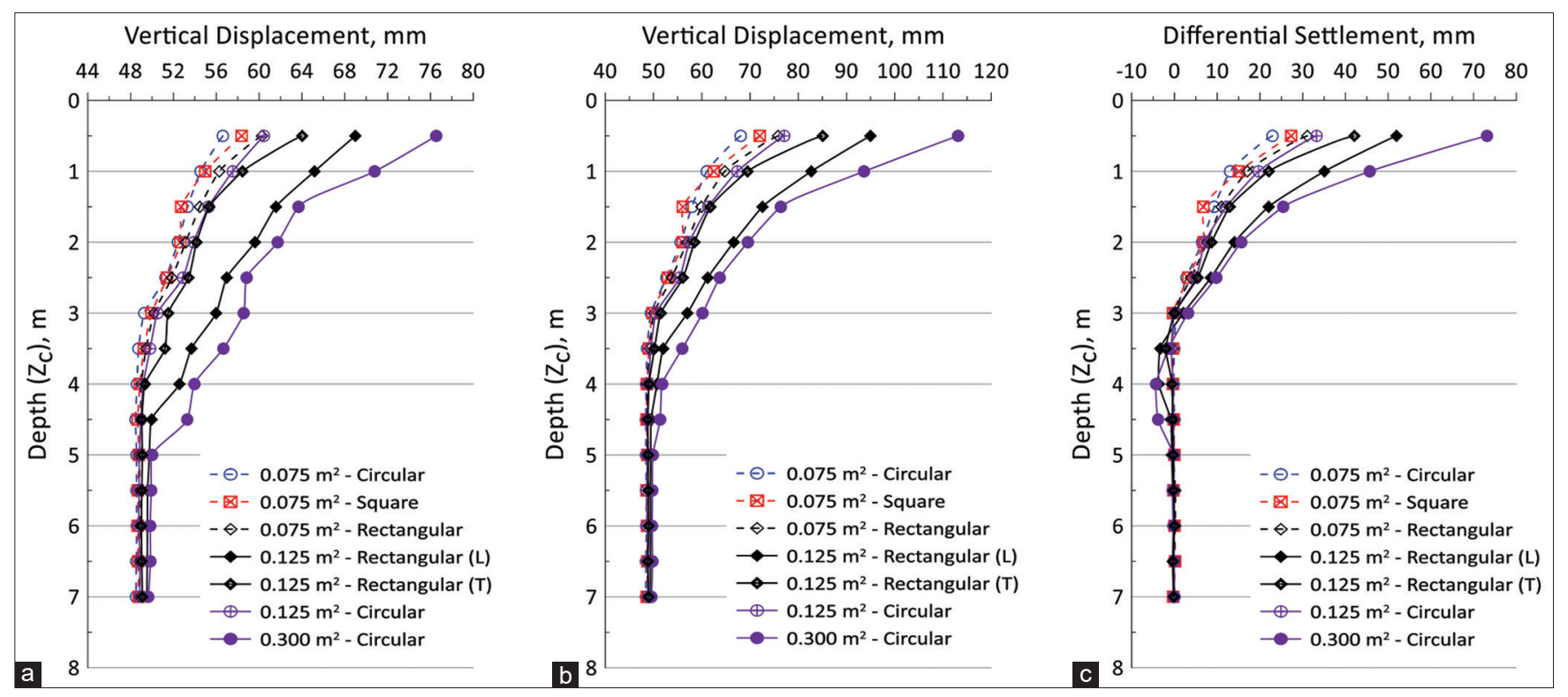

Figure 8: Variation of vertical and differential settlements of the footing with $Z_{c}$ in all seven scenarios of the cavity located at $X_{c}=1.0 \mathrm{~m}$. (a) Point B (Mid-point) (b) Point C (c) Differential settlement 
settlements show remarkable reversal trends for shallow depth scenarios of cavities with $X_{C}>1 \mathrm{~m}$.

\section{Effects of distance of cavity on settlement}

Figure 10 shows the variation of settlement with distance from center of footing for the small circular cavity in Case- 1 at different depths $0.5 \mathrm{~m}, 1.0$, and 1.5 below the ground surface. The selected horizontal positions $\left(X_{\partial}\right)$ in this parametric analysis are in the range between 0.0 and $4.0 \mathrm{~m}$ with $0.5 \mathrm{~m}$ intervals. It is clearly seen that the effects of the cavity are reduced by increasing the distance from the centerline of the footing or loaded area, for all the studied depths. In the case of $Z_{C}=0.5 \mathrm{~m}$, the calculated differential settlements of the footing are $0.1,9.2,22.9,2.0$, and $0.3 \mathrm{~mm}$ for $X_{C}$ equal to $0.0,0.5,1,1.5$, and $2.0 \mathrm{~m}$, respectively; and it remains almost unchanged with no differential settlement with a further increase of the distance. The corresponding differential settlement values for the scenario with $Z_{C}=2 \mathrm{~m}$, are $0.3,6.9,6.6,0.3$, and $0.08 \mathrm{~mm}$ with the similar $X_{C}$ distances $0.0,0.5,1,1.5$, and $2.0 \mathrm{~m}$.

Settlement-analysis curves for other competing cases of cavities of different shapes yielded a similar tendency with $X_{C}$-distance [Figure 11]. In different sets of simulation runs, the analysis of each of these cases is performed by varying their $X_{C}$ values (between 0.0 and $4.0 \mathrm{~m}$ ) while keeping their depth $\left(Z_{C}\right)$ fixed at $1.0 \mathrm{~m}$ below the ground surface. All these indicate that the effects of the cavity are more significant when it is situated at distances between $0.5 \mathrm{~m}$ and $1.0 \mathrm{~m}$; and are negligible at distances $>2 \mathrm{~m}(\approx \mathrm{B})$. After

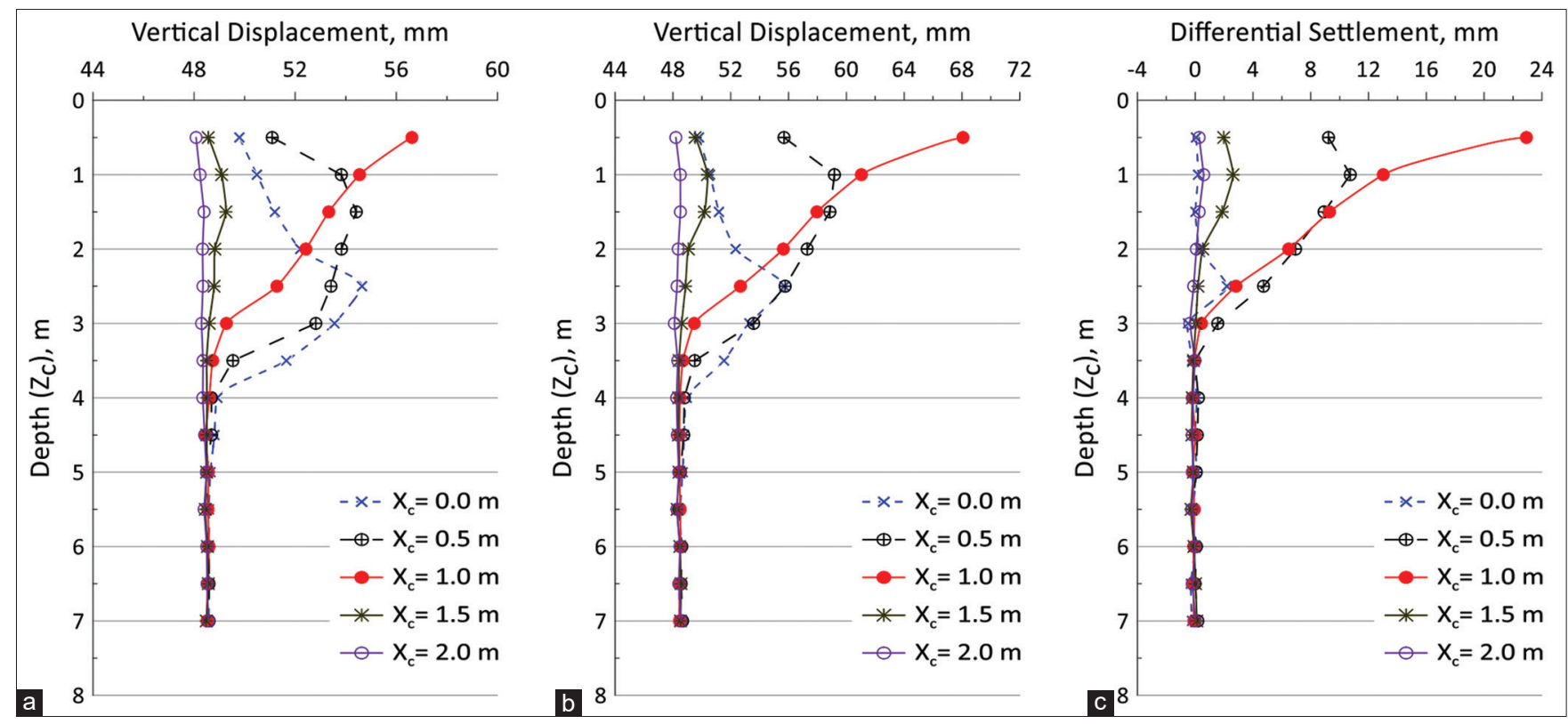

Figure 9: Variation of vertical and differential settlements of the footing with $Z_{c}$ in Case-1 of a small circular cavity located at various $X_{c}$-distances. (a) Point B (Mid-point) (b) Point C (c) Differential settlement
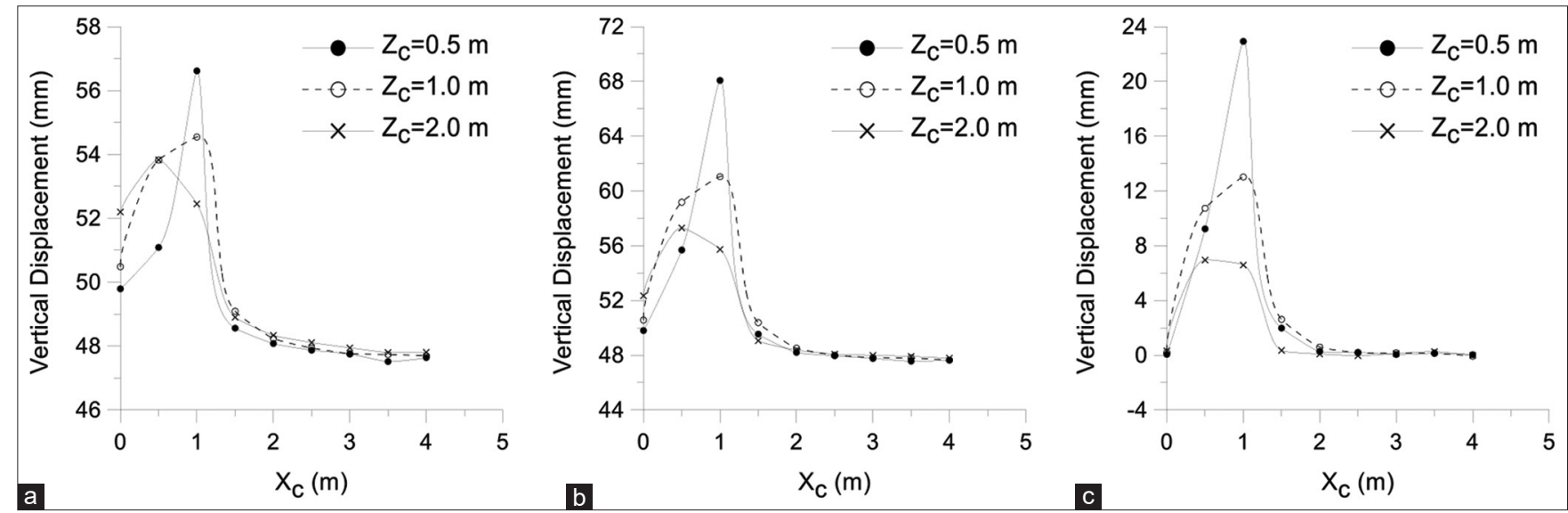

Figure 10: Variations in vertical and differential settlements of the footing versus $X_{c}$ in Case-1 of a small circular cavity placed at various $Z_{c}$-depths. (a) Point B (Mid-point) (b) Point C (c) Differential settlement 
that, the curves continue their declining trend and remain almost unchanged at zero (i.e. no-differential settlement with small fluctuations) as the $X_{C}$ increases. In this way, the boundary of the critical zone in the horizontal direction can be identified to be $X_{C} \leq \mathrm{B}$, where within this zone the potential risk of settlement is high. This changing trend in the results is due to that when the cavity is placed under the stressed zone of footing and at one side of its vertical axis $\left(0<X_{C} \leq 1 \mathrm{~m}\right)$ the lateral walls of the cavity become unstable due to shear strain growth between the cavity and the strip footing (Lavasan et al., 2016). Under this condition, the developed shear band approaches toward the cavity sides (i.e. causes a failure mode) and thus a larger settlement occurred in the footing. On the other hand, by increasing the distance between the cavity and the stressed zone due to the footing loading $\left(X_{C}>1\right)$ the overall strain of the cavity walls is decreased and the settlement analysis of the footing is converged to the case with no cavity condition.

\section{Effects of size and shape of the of cavity on settlement}

Comparison of the above results for different shapes of the cavity in Cases 1, 2, and 3 with the same cross-sectional area shows that, generally, circular, or rounded shape cavity results in a lower settlement than other shapes. This also can be found in the results for other large-sized cavities in Case- 4 of rectangular $(25 \mathrm{~cm} \times 50 \mathrm{~cm})$ and Case- 6 of circular $(19.9 \mathrm{~cm}$ diameter $)$ shapes, with the same crosssectional area of $0.125 \mathrm{~m}^{2}$. Accordingly, the settlement induced by the circular cavity is significantly lower than the case with the rectangular shape, especially at shallow depths and at horizontal locations close to the footing centerline.

The rectangular-shaped cavities in Case- $4(25 \mathrm{~cm} \times 50 \mathrm{~cm})$ and Case- $3(25 \mathrm{~cm} \times 30 \mathrm{~cm})$ are longitudinally oriented in the model, and they have the same width of $25 \mathrm{~cm}$ in their transverse directions. Comparing the results of these cases shows that Case- 4 of medium-size rectangular cavity leads to a larger amount of settlement than the related small rectangular in Case-3, indicating that the length of the cavity in direction perpendicular to the loading action plays a dominant role in the settlement of footing. To generalize this claim, in another scenario, in Case-5, a rectangular-shaped cavity with the equivalent dimensions as in Case-4 $(25 \mathrm{~cm} \times 50 \mathrm{~cm})$ is placed transversely in the model, whereby its length is parallel to the loading axis. The contours of the settlement for different $Z_{c}$-depths in these two cases of rectangular cavities are revealed in Figure 12. This new scenario (Case-5) undergoes a lower settlement than the other one. This can be attributed to the effects of lateral stresses. In other words, the lateral confining stresses on the cavity sides in the vertical direction cause a reduction in settlement value. By virtue of this, in Case- 5 with the transverse cavity, a larger boundary of the cavity in vertical direction is provided to deal with the lateral pressure and thus the lower settlement values are warranted. It is clear from the results that increasing the size of cavities in Cases- 6 and 7 is associated with a substantial increase of the settlement; this is with respect to the small size cavity in Case-1 of the same circular-shaped geometry [Figure 13].

\section{Low Stiffness Layer within the Model}

In this section, the impact of stiffness and depth $\left(Z_{w k}\right)$ of $1 \mathrm{~m}$-thick weak layer on the displacement of the same strip footing is studied. The weak layer is defined by adopting an -value less than the reference problem (i.e. $E=10000 \mathrm{kN} / \mathrm{m}^{2}$ ). The depth $Z_{w / k}$ is measured from the ground surface to the top of the weak layer. The shear strength parameters of this layer are $15 \mathrm{kN} / \mathrm{m}^{2}$ and $10^{\circ}$ as cohesion intercept and angle of shearing resistance respectively. All other parameters are kept unchanged as in the original problem.

\section{Effects of stiffness of weak layer}

The weak layer is defined within the soil profile at different depths (ranged between 0.5 and $6.5 \mathrm{~m}$ ) and with different
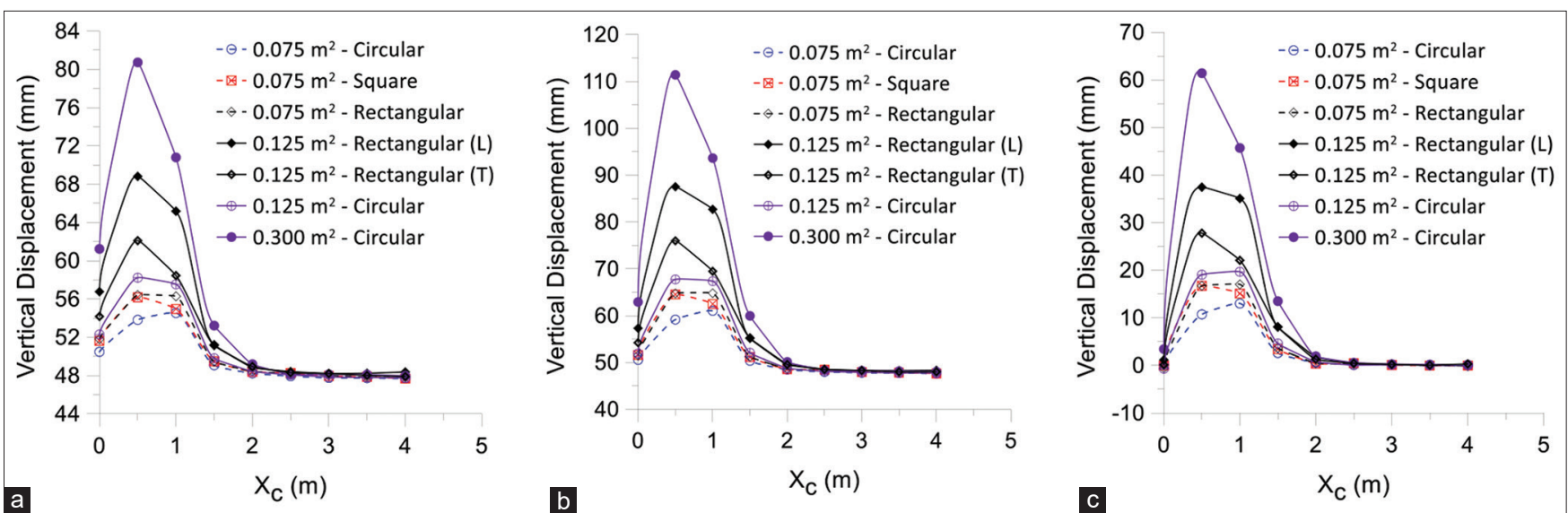

Figure 11: Variations in vertical and differential settlements of the footing versus $X_{c}$ in all seven scenarios of the cavity situated at depth $Z_{c}=1.0 \mathrm{~m}$ (a) Point B (Mid-point) (b) Point C (c) Differential settlement 

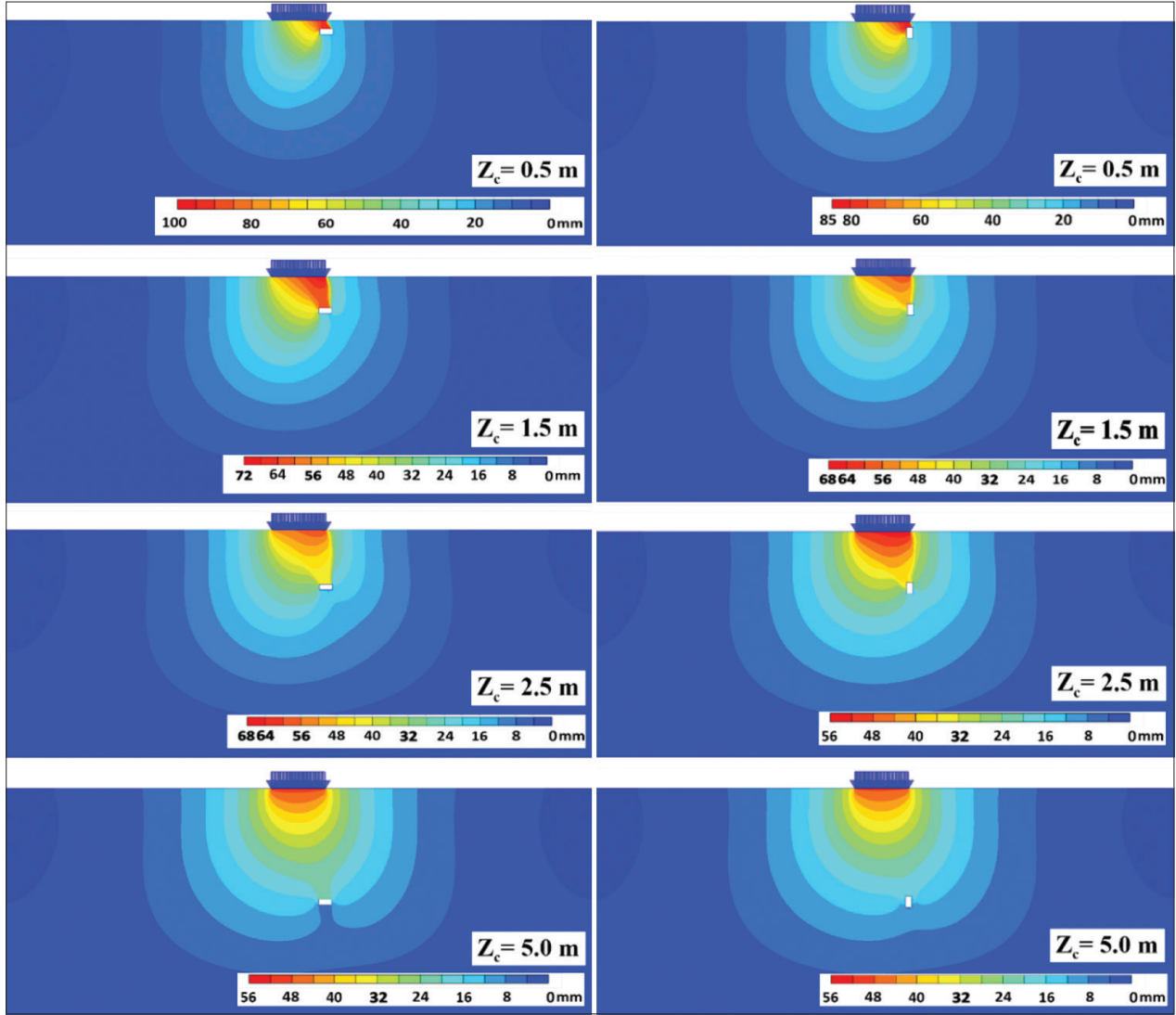

Figure 12: Effects of cavity orientation on the settlement profile in Case-4 (Iongitudinal cavity) and Case-5 (transverse cavity)
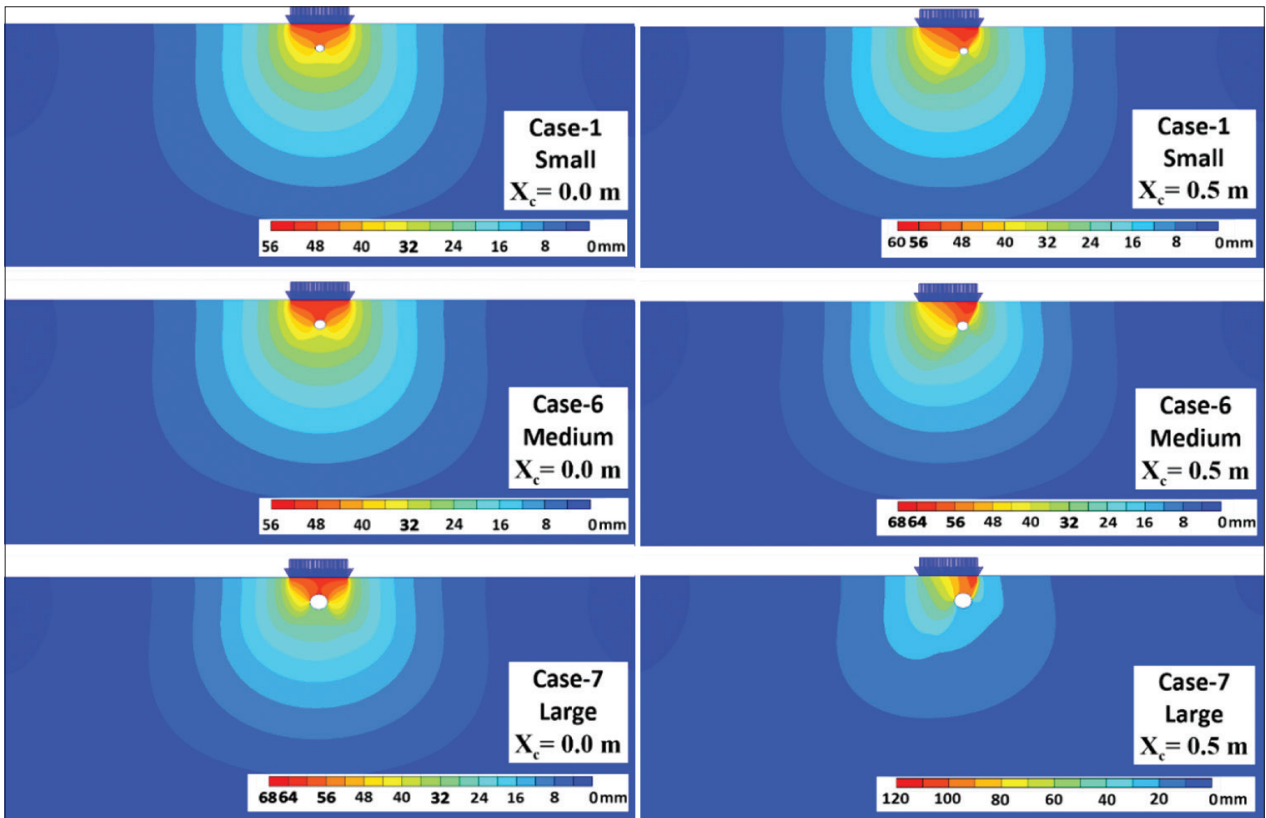

Figure 13: Effects of spacing of different-sized circular cavities on the shadings of the settlement

values of modulus of elasticity (E) 2000, 3000, 4000, 5000, 6000,7000 , and $8000 \mathrm{kN} / \mathrm{m}^{2}$. The seven selected depths for the weak layer are $0.5,1.5,2.5,3.5,4.5,5.5$, and $6.5 \mathrm{~m}$. Figure 14 summarizes these variations in terms of maximum settlement observed at the center of footing. In addition, Figure 15 shows the contours of variation of settlement for cases with $E=2000,3000,5000$, and $8000 \mathrm{kN} / \mathrm{m}^{2}$, and when $Z_{w / k}$ is at $1.5 \mathrm{~m}$ below the ground surface. 


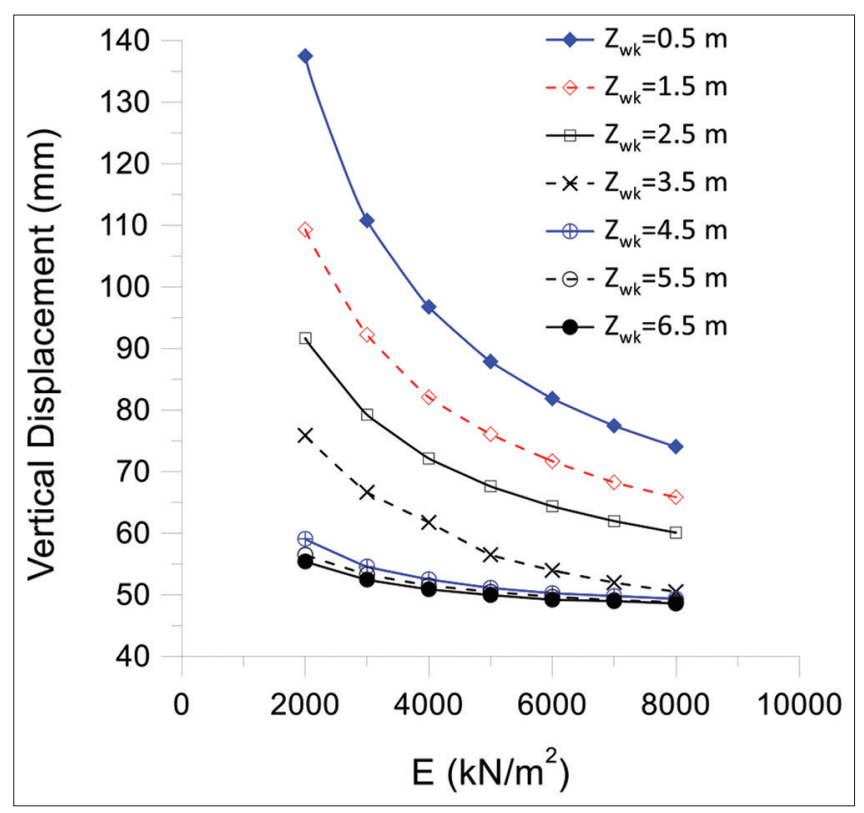

Figure 14: Effects of stiffness of weak layer on settlement of footing

It is obvious from the results that the large degree of weakness of the weak layer (i.e. lower stiffness) increases the settlement. In the worst-case scenario (top curve in Figure 14) with $Z_{w k_{k}}=0.5 \mathrm{~m}$, the largest amount of settlement at the center of footing is calculated as $137.5 \mathrm{~mm}$ for the case with $E=2000 \mathrm{kN} / \mathrm{m}^{2}$. This is equivalent to more than a threefold increase in the amount of settlement in comparison with the case with no-weak layer, $(47.6 \mathrm{~mm}$ settlement). The lowest value of settlement is calculated to be $74.0 \mathrm{~mm}$ for the case with $E=8000 \mathrm{kN} / \mathrm{m}^{2}$ and for the same depth of weak layer $Z_{w k}=0.5 \mathrm{~m}$.

During the simulation of the soil-foundation system for stiffness values lower than $2000 \mathrm{kN} / \mathrm{m}^{2}$, the calculations are failed to converge due to collapse of the soil body. In general, the simulated amounts of differential settlement are insignificant in these tested models; and the center of footing is almost the location of the maximum settlement in all of these cases. In accordance with these results, the values of differential settlement are $<10 \mathrm{~mm}$ toward the right corner (point $\mathrm{C}$ ) in cases of weak layer with values $=2000$ and $3000 \mathrm{kN} / \mathrm{m}^{2}$ placed at depth $0.5 \mathrm{~m}$. In these scenarios, the footing undergoes the largest values of differential settlement, which are still comparatively low.

\section{Effects of depth of weak layer}

In different representations of the results, the effects of depth of the weak layer $\left(Z_{w k}\right)$ below the strip footing for all values of stiffness $(E)$ are assessed in this section. The effect of weak layer on the general displacement of the footing is reduced by its presence at a greater depth, where the settlement is reduced substantially with depth [Figure 14]. A major factor contributing to this decline

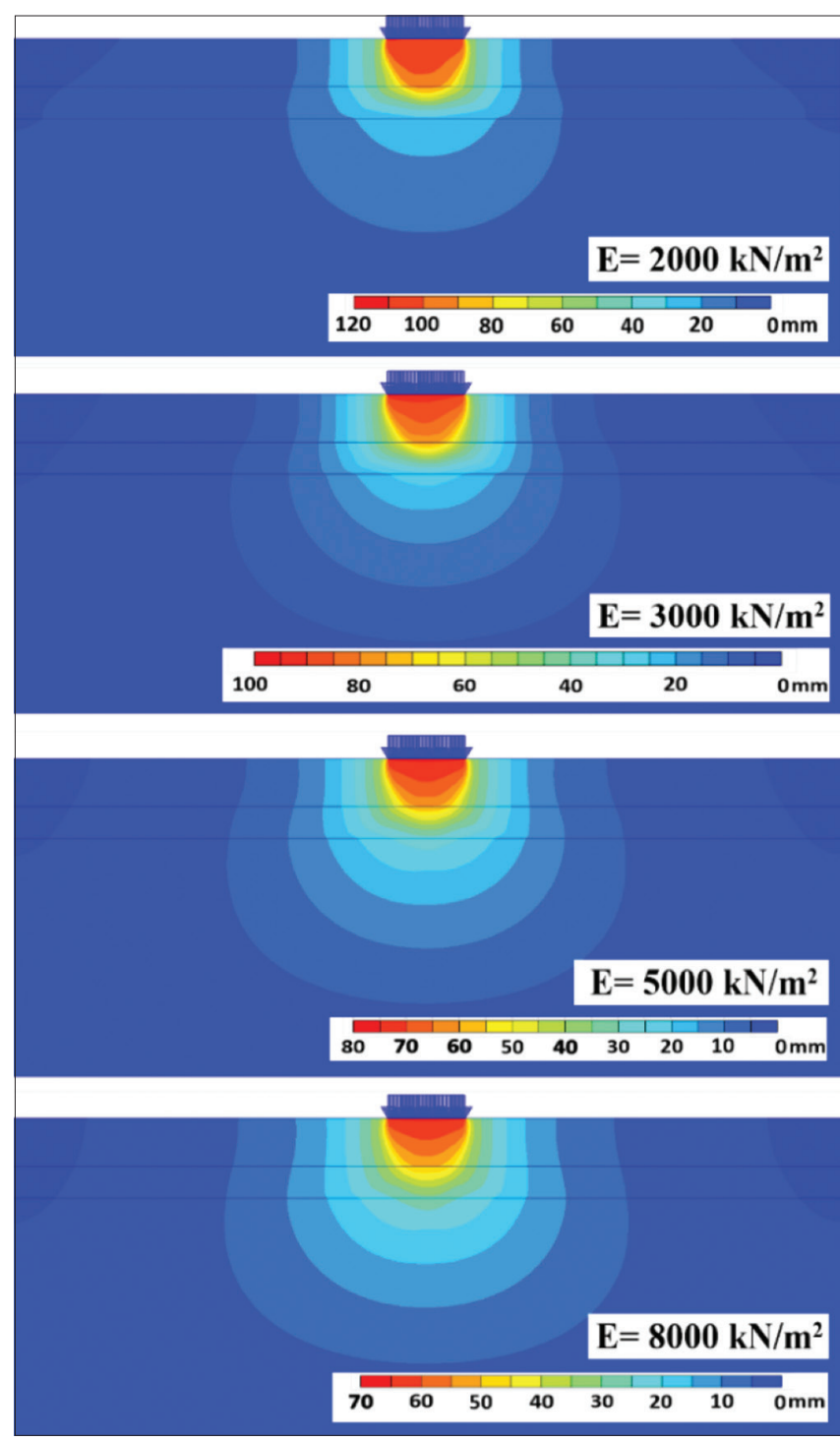

Figure 15: Shadings of the displacement for the case of weak layer soil located at $Z_{w k}=1.5 \mathrm{~m}$ and with different $E$ values

is the stiffness of the weak layer. For instance, for the case with $E=2000 \mathrm{kN} / \mathrm{m}^{2}$ and when the weak layer is at $0.5 \mathrm{~m}$ below the footing, the total displacement value at the center of the footing is $137.7 \mathrm{~mm}$, but it causes a $55.4 \mathrm{~mm}$ settlement when it is at $6.5 \mathrm{~m}$ below the ground surface. Nevertheless, for the case with $E=8000 \mathrm{kN} / \mathrm{m}^{2}$ this value is reduced from $74.0 \mathrm{~mm}$ at $Z_{w / k}=0.5 \mathrm{~m}$ to $48.6 \mathrm{~mm}$ at $Z_{w k}=6.5 \mathrm{~m}$.

Although the rate of this decline is reduced by increasing the stiffness of the weak layer, the effect of weak layer on the footing stability is noticeable even if it is founded deep within the soil layer. This is with reference to the control scenario with no weakness. However, the critical depth of occurrence of weak layer in subsoil, which induces the most of the settlement, is at depth $<4.5-5.5 \mathrm{~m}(\approx 2.5 \mathrm{~B})$ below the foundation level. 


\section{CONCLUSIONS}

In this study, it has been shown that the shape, size, depth, and distance of cavity from the loaded area play an important role in vertical settlement responses of the footing. The existence of a cavity in the soil profile within the stressed zone of the footing can have serious effects on the stability of the whole structure built on it, whilst at larger depths and distances away from the footing the impacts of the cavity presence become less considerable. The majority of the settlements induced by the cavity are for the cases with the cavity placed at depths smaller than $2.5 \mathrm{~B}$ and at horizontal distances smaller than $B$ from the center of footing. In addition, within this zone, the risk of differential settlement is high. Therefore, this area is a critical zone for settlement, to which a particular attention should be paid during the design of shallow footing resting on soils with cavity. It was also found that the overall settlement of the foundation could be seriously increased if a weak layer of low stiffness is located at shallow depth below the footing. Based on the obtained results, it is recommended that in the future studies, the same parametric study should be conducted for other types of shallow foundation to generalize the defined critical zone. Furthermore, the role of the water table on the safety of these footings in weak soils should be investigated.

\section{REFERENCES}

Al-Jazaairry, A. A. and T. T. Sabbagh. 2017. Effect of cavities on the behaviour of strip footing subjected to inclined load. Int. J. Civil Environ. Struct. Construct. Architect. Eng. 11(3): 292-298.

Al-Taie, S. M. 2004. The Performance of Laterally Loaded Piles Embedded in Sandy Soils Which Contains Cavities. M. Sc. Thesis. Civil Engineering Department, University of Baghdad, Iraq.

Augarde, C. E., A. V. Lyamin. and S. W. Sloan. 2003. Prediction of undrained sinkhole collapse. J. Geotech. Geoenviron. Eng. 129(3): 197-205.

Coduto, D. P., W. A. Kitch and M. C. R. Yeung. 2016. Foundation Design: Principles and Practices. $3^{\text {rd }}$ ed. Pearson Education, Inc., Upper Saddle River, NJ.

Farid, A. T. M. 2015. Settlement of Shallow Foundations Placed on Limestone Rock Formations with Open or Closed Cavities. Proceedings of the $6^{\text {th }}$ Jordanian International Civil Engineering Conference (JICEC06), Amman, Jordan.

Fattah, M. Y., K. H. I. Al Helo and H. H. Abed. 2018. Load distribution in pile group embedded in sandy soil containing cavity. KSCE J. Civil Eng. 22(2): 509-519.

Fattah, M. Y., K. H. I. Al-Helo and H. H. Abed. 2014. Effect of cavity in sandy soil on load distribution of pile group. Eng. Technol. J. 32(7): 1733-1751.

Ghazavi, M. and Y. Soltanpour. 2008. Effect of Cavity on Bearing Capacity of Shallow Foundations in Geotextile-reinforced Soil. Proccedings of the $12^{\text {th }}$ International Conference of International Conference of International Association for Computer Methods and Advances in Geomechanics (IACMAG), Goa, India.

Hossain, M. S., M. F. Randolph, Y. Hu and D. J. White. 2006. Cavity Stability and Bearing Capacity of Spudcan Foundations on Clay. Paper Presented at the Offshore Technology Conference, Houston, Texas, USA.

Kapoor, A., B. S. Walia and C. Singh. 2019. Effect of cavity on bearing capacity of shallow foundation in reinforced soil. In: Singh, H., P. Garg and I. Kaur, editors. Proceedings of the $1^{\text {st }}$ International Conference on Sustainable Waste Management through Design. Springer International Publishing, Cham. p313-322.

Khattab, S. I. and A. A. Khalil. 2009. Effect of cavity on stress distribution and settlement under foundation. AL Rafdain Eng. J. 17(6): 14-29.

Lavasan, A. A., A. Talsaz, M. Ghazavi, and T. Schanz. 2016. Behavior of shallow strip footing on twin voids. Geotech. Geol. Eng. 34(6): 1791-1805.

Luo, W., M. Zhao, Y. Xiao, R. Zhang and W. Peng. 2019. Seismic bearing capacity of strip footings on cohesive soil slopes by using adaptive finite element limit analysis. Adv. Civil Eng. 2019: 4548202.

Peng, F. L., M. Kiyosumi, M. Ohuchi and O. Kusakabe. 2006. Cavity effects on the bearing capacity of footing foundations and the calculation method. In: Underground Construction and Ground Movement. ASCE Library, North America.

Poulos, H. G. and E. H. Davis. 1974. Elastic Solutions for Soil and Rock Mechanics. Wiley, United States.

Sabouni, R. and M. Airan. 2018. Evaluation of foundation on soil with cavities: A case study from the UAE. Int. J. Struct. Civil Eng. Res. 7(4): 358-363.

Schanz, T. and H. H. Karim. 2018. Geotechnical Characteristics of Some Iraqi Gypseous Soils. Vol. 162. MATEC Web of Conferences, EDP Sciences, France. p01005.

Tahmasebipoor, A., R. Noorzad, E. Shooshpasha and A. Barari. 2012. A parametric study of stability of geotextile-reinforced soil above an underground cavity. Arab. J. Geosci. 5(3): 449-456.

Wang, M. C., Y. U. Kim. and J. T. Jun. 2001. Cavity Effect on Collapse Load of Strip Footings. Proceedings of $15^{\text {th }}$ International Conference on Soil Mechanics and Geotechnical Engineering, Istanbul, Turkey.

Zhao, L., S. Huang, Z. Zeng, R. Zhang, G. Tang and S. Zuo. 2021. Study on the ultimate bearing capacity of a strip footing influenced by an irregular underlying cavity in karst areas. Soils Found. 61(2): 259-270. 